\title{
Developing capacity to care for clients at risk for delirium and for acutely delirious clients
}

\author{
Sherida Ingram, Yolanda Babenko-Mould , Richard Booth \\ Arthur Labatt Family School of Nursing, Faculty of Health Sciences, Western University, London, Ontario, Canada
}

Received: July 12, 2015

DOI: $10.5430 /$ jnep.v6n3p122
Accepted: November 22, $2015 \quad$ Online Published: December 2, 2015

URL: http://dx.doi.org/10.5430/jnep.v6n3p122

\begin{abstract}
The purpose of this mixed-methods study was to assess nurses' $(\mathrm{N}=56)$ knowledge and self-efficacy of: a) caring for clients experiencing delirium, and b) caring for clients at risk of developing delirium in a hospital setting. Nurses completed study instruments prior to and immediately after taking part in a clinical education session. Seven nurses participated in a follow-up interview to explore their experiences of applying knowledge from the education session to the practice setting. Objectives of the education session included reviewing risks, signs, symptoms, standardized screening tools, and management strategies for clients at risk for or experiencing delirium in a hospital setting. Nurses were found to have improved knowledge and self-efficacy, as to the recognition and management of delirium. The qualitative findings highlighted nurses' rich experiences and revealed themes, namely, enhancing emotional intelligence, strengthening clinical judgment to enhance quality of care, and increasing competency for family care. This study demonstrates how continuing education in clinical practice can positively impact nursing knowledge, confidence, and application of knowledge into practice in efforts to decrease the prevalence of delirium. As such, an investment in continuing professional development education for delirium recognition and management is proposed to be a strategy that can positively impact client care.
\end{abstract}

Key Words: Nurses, Delirium, Education, Clients, Acute care, Knowledge, Self-efficacy, Mixed-methods

\section{INTRODUCTION}

Delirium, first identified by Hippocrates more than two thousand years ago, has been recognized to be one of the earliest described medical phenomena. ${ }^{[1-3]}$ As one of the most common complications experienced by older hospitalized clients, ${ }^{[3-5]}$ the delirium incidence rate is reported to be as large as $20 \%$ to $53 \%$ of clients in hospital. ${ }^{[2,6-8]}$

Resulting from a combination of clinical insults such as acute illness, environmental changes, sleep deprivation, medications, and medication changes, delirium is described as a multi-factorial syndrome. ${ }^{[9]}$ Diagnosis includes acute onset, fluctuating course, physical etiology, global cognitive impairment, disturbance of attention, and disturbance of the sleep-wake cycle. ${ }^{[4,7,10,11]}$ The Diagnostic and Statistical Manual of Mental Disorders, 4th Edition, Text Revision (DSM-IV-TR) "defines delirium as: (a) a disturbance of consciousness (i.e., reduced clarity of awareness of the environment, with reduced ability to focus, sustain or shift attention; (b) a change in cognition (such as memory deficit, disorientation, language disturbance) or the development of a perceptual disturbance; and (c) the disturbance develops over a short period of time (usually hours to days) and tends to fluctuate during the course of the day". ${ }^{[12]}$

Delirium is a temporary condition and is often confused with other cognitive disorders, such as dementia, which is chronic and progressive. ${ }^{[13]}$ Subdivided into three categories, delir-

\footnotetext{
* Correspondence: Yolanda Babenko-Mould, RN, BScN, MScN, PhD; Email: ybabenko@uwo.ca; Address: Arthur Labatt Family School of Nursing, Faculty of Health Sciences, Western University, London, Ontario, Canada.
} 
ium is classified as hyperactive, hypoactive, or mixed ${ }^{[14,15]}$ which can add to the difficulty of diagnosis. Many of the associated risk factors of delirium are closely linked to the characteristics of dementia, and other psychiatric disorders, leading to the complexity in generating a diagnosis. ${ }^{[16]}$

Examining differences in the symptoms of the three categories of delirium may increase nurses' comprehension and consequently the recognition of delirium. Hyperactive delirium symptoms include sympathetic nervous system over-activity, such as verbal or physical aggression, agitation, restlessness, wandering, psychomotor hyperactivity, increased alertness to stimuli, mood liability, euphoria and anger. ${ }^{[14,16,17]}$ Hypoactive delirium symptoms include lethargy or somnolence, withdrawal, decreased responsiveness to stimuli, apathy, psychomotor hypoactivity, clouded inattention, slow speech and the client may be difficult to arouse. ${ }^{[14,16,17]}$ Hypoactive symptoms are thought to be more difficult to diagnose and may be misdiagnosed as depression or simple fatigue. ${ }^{[14,16,17]}$ Mixed delirium is demonstrated by evidence of signs and symptoms from both hyperactive and hypoactive delirium.

Regardless of the classification (hyperactive, hypoactive, or mixed) there is significant variability in the clinical course and manifestation of the condition. ${ }^{[17]}$ Full recovery from delirium is possible with early detection and intervention. ${ }^{[17]}$ Conversely, progression to stupor, coma, seizures and even death are also possible. ${ }^{[8,17]}$ Early recognition and management is likely to reduce the incidence and progression of associated co-morbidities of delirium. ${ }^{[8]}$ Because of its seriousness and potential reversibility ${ }^{[8]}$ it is important that nurses, as 24-hour caregivers, possess the competence (knowledge) and confidence (self-efficacy) to assess, screen, and manage the care of clients at risk for or experiencing delirium.

It has been suggested that prevention and recognition of delirium in clinical environments begins with education about the condition. ${ }^{[8,18]}$ Therefore, the authors developed and implemented an educational session for nurses about delirium as part of a mixed-methods study. In particular, objectives of the education session included reviewing risks, signs, symptoms, standardized screening tools, and management strategies for clients at risk for or experiencing delirium in a hospital setting. The purpose of the mixed-methods study was: (a) to assess nurses' knowledge and self-efficacy of caring for clients experiencing delirium and those at risk of developing delirium in a hospital setting prior to and immediately after taking part in a clinical education session; and (b) to explore nurses' experiences of applying knowledge from the education session to the practice setting. It is proposed

Published by Sciedu Press that assessment of nurses' knowledge of and self-efficacy for caring for the acutely delirious client and an exploration of nurses' experience of the translation of knowledge about delirium into practice can provide a deeper understanding of how knowledge development can ultimately improve nursing practice.

\subsection{Theoretical framework}

Bandura's ${ }^{[19,20]}$ theory of self-efficacy was selected as the theoretical framework for this study. The theoretical lens is founded on the concept that perceived self-efficacy is understood to be a belief in one's own capabilities to organize and execute the courses of action required to manage future situations. ${ }^{[20]}$ The concept of self-efficacy, derived from Bandura's ${ }^{[19,20]}$ Social Cognitive Theory, comprises three factors, namely, environmental, behavioral and cognitive, that interact in a reciprocal manner.

Bandura posits that most "external influences affect behaviour through intermediary cognitive processes" (p. 160) ${ }^{[19]}$ Cognitive processes can have an effect on which external event is observed, how the event will be perceived and whether there is any lasting effect as a result, what positive feeling and efficacy the event has, and how the information will be structured for the future. ${ }^{[19]}$ In the present study, Bandura' ${ }^{[19,20]}$ theory of self-efficacy was used to assist in the understanding of the cognitive factor related to perceptions of nurses' self-efficacy prior to and after an education session about caring for at risk clients and for those clients experiencing acute delirium.

\subsection{Literature review}

\subsubsection{Self-efficacy in nursing}

Self-efficacy was described by Zulkosky ${ }^{[21]}$ as a multifaceted concept that influences how one acts, feels, thinks, and motivates oneself; a concept that is fundamental in nursing education. ${ }^{[22]}$ Robb $^{[22]}$ conducted a concept analysis exploring self-efficacy and its relationship to nursing education, and the role self-efficacy plays in both the cognitive and affective processes. Robb ${ }^{[22]}$ determined that one chooses courses of action dependent upon skills and abilities that one feels they possess. Promoting confidence often requires a change in behaviour. When discussing the continuing education of nurses, Zulkosky ${ }^{[21]}$ noted that self-efficacy is an important concept that effects the actions nurses engage in and consequences related to patient care outcomes. The concept of self-efficacy has been examined in previous research in nursing, ${ }^{[23-25]}$ and enhanced self-efficacy in nursing has been found to lead to a belief that one can engage in certain actions in order to attain desired outcomes.

Jordan and $\mathrm{Church}^{[23]}$ examined outcomes of the effective- 
ness of a therapeutic learning activity designed to increase the self-efficacy of students $(\mathrm{N}=39)$ in meeting the psychosocial needs of clients with dementia. The authors evaluated: (1) discussions with students before and after the learning activity, (2) observations of students' performance during the activity, (3) results of a self-efficacy survey administered prior to and following the learning activity, and (4) completion of a clinical log addressing the major objectives of the activity. Discussions with students prior to the learning experience supported previous research; many students acknowledged negative feelings in relation to not feeling confident about meeting psychosocial needs of clients with dementia. Over $50 \%$ of the students expressed positive feelings after engaging in the learning activity. Survey results showed a statistically significant improvement in students' self-efficacy; pretest $(\mathrm{M}=35.08, \mathrm{SD}=4.80)$ to posttest $(\mathrm{M}$ $=42.10, \mathrm{SD}=4.29), t(38)=10.568, p<.0001$. Furthermore, mean difference in pre-test and post-test scores was -7.03 with a $95 \%$ confidence interval $[5.68,8.37]$. The log entries required the students to discuss thought and feelings about the experience. Of the 39 entries, 37 were positive, sharing feelings of the experience being enjoyable and that they (students) noticed a change in clients' attitudes as a result of participating in the activity. Study findings provide support for the view that clinical experiences that address the psychosocial needs of clients with dementia can strongly affect student attitudes. The change in attitude noted can translate into increased self-efficacy in students, which could develop into the provision of more effective psychosocial care for patients, and positive clinical experiences for nursing students when caring for clients with dementia.

Roh, Lee, Chung and Park ${ }^{[24]}$ used a comparative design and random assignment with nurses $(\mathrm{N}=38)$ who were educated about resuscitation techniques delivered via computer-based simulation $(\mathrm{n}=18)$ or mannequin-based simulation $(\mathrm{n}=20)$ to measure self-efficacy of nurses' perceptions of their capability to organize and execute a course of action in dealing with cardiac arrest situations. Nurses in both groups reported similar levels of self-efficacy for engaging in advanced life support behaviours post-education (overall average of 6.40 on a 10 point scale with higher values associated with higher self-efficacy). In addition, nurses in both groups reported similar levels of satisfaction with simulation usefulness and satisfaction with instructional design (overall average of 7.53 on a 10 point scale with higher levels indicating higher satisfaction). Study findings provide support to the notion that educational interventions that include simulation, independent of the method of instruction (computer versus hands-on) can increase nurses' self-efficacy to engage in behaviours that can positively impact patient care practices.
Stanley and Pollard ${ }^{[25]}$ used a cross-sectional correlational design with a convenience sample of pediatric nurses $(\mathrm{N}=$ 25) from two hospitals in the same region in the Southern United States. The purpose of Stanley and Pollard's ${ }^{[25]}$ study was to measure nurses' knowledge of and their self-efficacy for managing pediatric pain. Results of the study found that nurses at both hospitals reported moderate levels of knowledge about pediatric pain management. However, there was a significant difference in levels of knowledge of pediatric pain management between the two hospital sights (hospital one $\mathrm{M}=27.08$ and hospital two $\mathrm{M}=24.83, \mathrm{SD}=2.93, t=2.044$, $p=.05)$. Nurses at both sites reported similar high levels of self-efficacy for pediatric pain management (hospital one $M=25.69$ and hospital two $M=26.92$ ). The researchers proposed the need for nurses to receive continuing education in practice about pain control to enhance knowledge and maintain subsequent strong levels of confidence for pain management. This study highlights the need for continuing professional development and to assess for a relationship between nurses' knowledge and self-efficacy in order to avoid situations where nurses feel over-confident without requisite knowledge, so there exists a balance between knowledge and level of confidence to carry out actions in a safe and effective manner.

\subsubsection{Delirium educational interventions in nursing}

A limited number of studies, which involved educational interventions or sessions for nurses to gain knowledge and develop capacity to care for clients at risk for delirium and for those experiencing delirium, were located for review. Akechi and colleagues ${ }^{[26]}$ examined the usefulness of a newly developed delirium training program to improve nurses' $(\mathrm{N}=$ 390) self-confidence in caring for clients with delirium. ${ }^{[26]}$ Study results showed that participation in the educational program improved the self-confidence of nurses caring for delirious clients. ${ }^{[26]}$ The researchers noted that educating additional nurses to provide optimal care for the delirious client requires the establishment of a comprehensive and continual education program.

Meako, Thompson, and Cochrane ${ }^{[27]}$ employed a pre-testpost-test quasi-experimental design, with a convenience sample of orthopedic nurses $(\mathrm{N}=23)$ to describe their baseline knowledge about delirium experienced by orthopaedic patients, test the usefulness of an educational intervention, and describe factors associated with differences in nurses' baseline knowledge about delirium and the effectiveness of an educational intervention. Using an evidence-based intervention based on nationally recommended guidelines and a pre-test-post-test questionnaire containing ten multiplechoice questions developed by the first author (Meako), participants' knowledge of delirium was assessed. Meako and 
colleagues $^{[27]}$ found the educational intervention to be successful in that all participants' scores improved. Meako and colleagues $^{[27]}$ reported that irrespective of education, years of experience, or shift worked, RNs struggled with questions related to recognition of delirium, predisposing and precipitating risk factors, and medications that can contribute to delirium. Meako and colleagues ${ }^{[27]}$ concluded that the intervention enhanced nurses' knowledge and could therefore be useful to implement in an ongoing manner in continuing professional development education programs.

Lastly, Rudolph and colleagues ${ }^{[9]}$ presented a case-based review of a 68 year-old male admitted to hospital for elective peripheral artery bypass to examine the effects of postoperative delirium in hospitalized clients. Additionally, Rudolph and colleagues ${ }^{[9]}$ explored potential opportunities to optimize outcomes through identifying those at risk using validated assessment methods. Rudolph and colleagues ${ }^{[9]}$ found four factors that can predict delirium risk in hospitalized clients, namely cognitive impairment, severity of illness, visual impairment and dehydration. Recognition of these risk factors using assessment and screening tools may prevent further complications from delirium. Rudolph and colleagues ${ }^{[9]}$ stressed that the rapid changes in the understanding of delirium since the year 2000 are not fully integrated into practice. The researchers recommended that in order to optimize health outcomes in the delirious client, a greater focus needs to be placed on education of nursing students and to integrate education about assessing and managing delirium in continuous professional development (CPD) offerings to nurses in practice. ${ }^{[9]}$ Despite advances in knowledge concerning delirium, these changes have not been fully incorporated into nursing practice.$^{[9]}$ Because of this, there continues to be a need to educate nurses regarding assessment and management of the health issue of delirium.

To date, research about delirium reveals the importance of developing a deeper understanding related to the recognition of delirium through assessment, screening and managing the care of clients. Of the studies reviewed, each recommended the need for additional education for nurses. Although increased confidence and knowledge post-test was noted in studies about recognizing and managing delirium, there continues to exist limited theoretically grounded research that assesses change in knowledge and confidence. Also, there were no studies using a mixed methods approach that explored nurses' experience of caring for delirious clients after participating in a clinical education session pertaining to the recognition of delirium in hospitalized clients. It is proposed that increased knowledge about delirium can facilitate accurate and early diagnoses, and prevention of incidences or exacerbations of delirium.

\subsection{Knowledge translation and practice}

Knowledge translation can be interpreted to be the process needed to close the gap between evidence and decisionmaking within nursing care by transmitting knowledge into action. ${ }^{[28]}$ The Canadian Institutes of Health Research (CIHR) defines knowledge translation as "a dynamic and iterative process that includes the synthesis, dissemination, exchange and ethically sound application of knowledge to improve health, provide more effective health services and products, and strengthen the health care system" (p. 165). ${ }^{[28]}$ In the literature, a consistent theme was noted about how nurses have reported that the transfer of research findings into practice is a time-consuming, challenging, and prolonged process. ${ }^{[29-31]}$

Not only is the process of knowledge translation complex, accessing current information that is reliable and based on current research $^{[32]}$ is difficult for nurses on a regular basis due to client acuity and day-to-day workload issues. Researchers have estimated that $30 \%$ to $55 \%$ of clients in the United States and the Netherlands do not receive healthcare based on scientific evidence. ${ }^{[28,33,34]}$ It is proposed that similar estimates might exist in the Canadian context given similar work environment issues and barriers to accessing and using research in practice. The concept behind knowledge translation not only includes the dissemination of knowledge; it involves the use of knowledge in practice. ${ }^{[28,33]}$

Cummings and colleagues ${ }^{[35]}$ conducted a systematic review and meta-analysis of 26 studies that studied the effects of knowledge translation interventions involving healthcare providers, clients and their caregivers to improve cancer pain outcomes. Cummings and colleagues ${ }^{[35]}$ reported that knowledge translation interventions for cancer pain often, but not always, resulted in improved knowledge, skills and attitudes about pain control and improved pain related health. Cummings and colleagues ${ }^{[35]}$ proposed that educational interventions were most effective when they involved committed multidisciplinary teams of content experts, used pre-constructed educational materials and standardized delivery approaches of the material.

Horeczko, Enriquez, McGrath, Gausche-Hill, and Lewis ${ }^{[36]}$ reviewed charts of pediatric patients $(\mathrm{N}=528)$ who had been triaged through the emergency department to determine the ways in which nurses were applying their knowledge of pediatric assessment in practice by using the Pediatric Assessment Triangle (PAT) evaluation tool. The researchers found that the tool was valid in that nurses, overall, were able to use their knowledge to accurately note level of acuity of patients and pathophysiological issues experienced by children (respiratory, cardiopulmonary status, central nervous 
system/metabolic status). ${ }^{[36]}$ This study demonstrated how nurses' knowledge of pediatric nursing could be reflected in the application of assessment skills, which were recorded on a comprehensive evaluation tool.

Christensen ${ }^{[37]}$ offered a case exemplar regarding advance practice nurses' development of "Patient Group Directions (PGDs)", a form of a medical directive in Australia for treatments to be carried out by nurses. In particular, a team of Outreach nurses developed a PGD about provision of fluid boluses to patients encountered in their outreach practice without the need for individuals to seek a prescription first. Outreach team nurses who applied the use of PGDs to practice believed such a mechanism offered timely care to individuals in the community in order for those persons to be able to avoid hospitalization for more acute health issues exacerbated by a decrease in fluid volume. In addition, nurses were open to being involved in inter-professional teams to develop additional PGDs to promote effective and individualized care.

Upon reviewing the literature, no known research was found pertaining to how knowledge was applied to practice following an educational session specific to delirium or the care of the delirious client. Given the nature of negative outcomes associated with delirium, it is prudent to conduct research into how education can advance knowledge and confidence of health professionals, and also to learn about how that knowledge can be translated into practice. Such insights can support the development of ongoing educational sessions in multiple acute care settings, as an important step in the knowledge translation process.

\subsection{Statement of hypotheses and research question}

Based on the preceding review of literature, and Bandura' $\mathrm{s}^{[19,20]}$ Theory of Self-Efficacy, the following hypotheses were tested.

\subsubsection{Hypotheses}

1) Nurses will have a higher level of knowledge about the care of clients as it relates to the assessment, screening, and management of clients at risk of developing delirium and for clients experiencing acute delirium, after participating in an education session, than they did prior to the educational session. 2) Nurses will have a higher level of self-efficacy for assessment, screening, and management of clients at risk of developing delirium and for clients experiencing acute delirium after participating in an education session, than they did prior to the education session.

\subsubsection{Research question}

When conducting the literature search, no known evidence was found pertaining to nurses' experience of applying knowledge gained from clinical education specific to delirium or the care of the delirious client to practice. Therefore, this study proposed to address the following research question: What are nurses' experiences of caring for clients in hospital who are at risk for or those experiencing delirium, after they (nurses) have participated in an education session about delirium?

\section{METHODS}

A mixed-methods design was utilized in this study. In particular, an explanatory design ${ }^{[38,39]}$ was employed by the researcher, collecting quantitative and qualitative data sequentially. Following the explanatory design process ${ }^{[38,39]}$ both the quantitative and qualitative perspectives are collected and analyzed separately with findings from both methods addressing the overall purpose of the study.

For the quantitative portion of the study, participants completed instruments to assess knowledge and self-efficacy prior to and immediately after the education session. Objectives of the education session included reviewing risks, signs, symptoms, standardized screening tools, and management strategies for clients at risk for or experiencing delirium in a hospital setting. Descriptive statistics from these instruments were analyzed using the Statistical Package for Social Sciences (SPSS) Version 22 software. ${ }^{[40]}$ Pre and post-instrument score comparisons were made using paired $t$-tests.

For the qualitative study, a descriptive phenomenological perspective, as proposed by Sandelowski, ${ }^{[41,42]}$ was used to explore nurses' experiences of applying knowledge from the education session to the practice setting. Sandelowski ${ }^{[42]}$ discusses the value of qualitative descriptive studies being, not only in the knowledge that they can produce, but also as a medium for presenting and discussing research methods. Through descriptive phenomenological research, the goal of the researcher is to "enter another's world and discover practical wisdom, possibilities and understandings found there" (p. 496). ${ }^{[39]}$ This perspective was used to gain an understanding of the ways in which nurses ascribe caring for clients at risk for and those clients experiencing acute delirium after being involved in the education session. Descriptive content analysis was conducted with seven nurses. Interview data was transcribed to develop categories and themes related to nurses' experience of knowledge translation into practice.

\subsection{Setting and sampling strategy}

The researchers identified the geographical location of Southwestern Ontario in which to conduct the education sessions for this study. The selected acute care hospital sites are part of the Local Health Integration Network (LHIN). For the 
quantitative arm of the mixed methods study, a sample size calculation was undertaken. According to Cohen, ${ }^{[43]}$ in order to attain a power of 0.8 and an alpha of 0.05 , a sample size of $\mathrm{N}=72$ would be required for this study. Also, the G-Power online calculator was used to compute the sample size required for quantitative segment of the study. A medium effect size (0.6), an error of probability of $(\alpha=.05)$, a power of 0.80 , and selection of the one-tailed test option were elements used in the computation, which resulted in a recommendation of a sample size of 72 participants.

Two acute care hospitals in the LHIN were included in the study in order to achieve the recommended overall sample size of 72 participants for the quantitative pre-post instrument completion arm of the study. The first facility has 506 beds and the second has 372 beds. Between the two facilities there were 50,473 admissions in 2013 to 2014. A total of six education sessions were held; four sessions at the first facility and two at the second facility.

Initial recruitment of participants was carried out through direct contact with all surgical and cardiac unit coordinators and educators at the two participating acute care facilities. To gain access to all eligible RNs at the facilities involved in point-of-care-nursing practice the primary researcher contacted unit coordinators, and educators of all surgical and cardiac units within the two facilities. The study information was forwarded via email by unit coordinators and educators to nursing staff.

All eligible RNs at the acute care facilities involved in point of-care-nursing practice were invited to volunteer to participate in the education sessions, regardless of the number of years of experience, education completed to obtain license, age, or gender. Eligible RNs were also requested to participate in an individual interview a month after completing the study post-test to explore the ways in which they applied knowledge gained from the intervention to practice. Eligibility criteria included participants who were able to commit to the time required to be involved in the pre-test, education session, and post-test, and be willing to participate in the follow-up interview process. Participants needed to speak and understand English. Students participating in clinical placements as part of their educational experience were excluded from the study.

Each of the 56 participants from medical, surgical and cardiac units took part in one of the education sessions and completed the pre and post-test instruments during the session. The education sessions were held repeatedly, allowing participants to attend one session at their convenience. Participants were contacted via email one month after participating in the intervention to request their participation in a follow-up interview. The follow-up interviews provided the participants time to care for clients at risk or experiencing delirium in the hospital setting. Seven of the 56 participants who participated in the education session took part in the follow-up interview portion of the study.

\subsection{Instruments}

Two instruments designed by the primary researcher were utilized for the quantitative methods part of the study: 1) the Knowledge Instrument to Care for a Client at Risk for Delirium and of the Acutely Delirious Client, and 2) the SelfEfficacy Instrument to Care for a Client at Risk for Delirium and of the Acutely Delirious Client Instrument. Participants completed both instruments prior to and immediately after the education session.

The Pre-Test and Post-Test Knowledge Instruments to Care for a Client at Risk for Delirium and of the Acutely Delirious Client both consist of ten items and take approximately five minutes each to complete. Participants were asked to respond by selecting an option from $\mathrm{A}$ to $\mathrm{E}$ to questions related to their knowledge of the assessment, screening and management of those clients at risk for delirium and of those experiencing acute delirium. Content and development of questions was based on current literature and the Registered Nurses Association of Ontario (RNAO) Best Practice Guidelines (BPG ${ }^{[44]}$ about delirium, with specific content as to risk factors, methods of screening and management of delirium in the hospitalized client. This information was important for nurses to know in order that they may develop and perform nursing interventions to improve the outcomes of client care.

Content validity of the pre- and post-knowledge and pre- and post-self-efficacy instruments used in the study was assessed by ten RNs with varying degrees of education and specialties using a Likert-type scale ranging from 0 to 4 , where 0 represented not relevant and 4 represented highly relevant. The instruments were also evaluated by the same RNs for (a) clarity of directions for completion of the instrument, (b) clarity of the items, and (c) ease of response to each question. The RNs reported that the instrument structure and content aligned with developing knowledge about caring for the acutely delirious or those at risk for delirium, so that all participants involved may have an understanding of the potential consequences of the illness and appropriate measures to manage the outcomes of the clients. Based on the RNs' feedback, the full title of a screening tool was added to the instrument, with the acronym in brackets beside the full title for clarity.

The Pre-Test and Post-Test Self-Efficacy Instruments to Care for a Client at Risk for Delirium and of the Acutely Delirious 
Client both contain eight items and take approximately five minutes to complete. Participants were asked to indicate how confident they were that they believed they could perform the behaviours noted in the instrument items. Participants were requested to note their perceptions of level of confidence on a Likert-type 10-point scale ranging from 0 to 100 , where 0 represented not confident and 100 represented very confident.

The same ten RNs who had reviewed the pre and post-test knowledge instruments noted above assessed content validity of the self-efficacy instruments. The instruments were evaluated for clarity of directions, ease of providing answers to complete the instrument, clarity of the items, and the ease of response to each item. Based on feedback from reviewers, no alterations were made to the pre- and post-self-efficacy instruments.

\subsection{Data collection methods}

Upon receipt of ethics approval from the researchers' academic setting to conduct this study, approval from two practice settings recruited for the study was sought and received. An email containing the information about the study was sent to unit coordinators, and educators of all surgical and cardiac units within the two facilities. This email included the researchers' contact information and a request to reply via email if interested. Additionally, recruitment posters were distributed throughout the two facilities by the researcher. At each education session, a package was distributed to attendees containing the Letter of Information, the Consent Form, and the Demographic Questionnaire.

Participants were given the opportunity to attend a session of their choice. Information was provided to potential participants as they expressed interest as to potential dates. The sessions were held every Friday for a total of six weeks. The pre-test knowledge instrument and pre-test self-efficacy instrument were distributed by the primary researcher for completion by participants immediately before the education session. The post-test knowledge instrument and post-test self-efficacy instrument were distributed by the primary researcher for participant's completion immediately following the education session. A total of six education sessions were held; four sessions at the first facility and two at the second facility.

Fifty-six participants took part in the education sessions and completed the pre- and post-test instruments. Each education session was held as a face-to-face 60-minute "lunch and learn" session lead by the primary researcher. A preprepared slide presentation and the same case study were utilized in each session to ensure consistency of presented material. Given the time for participants to complete the pre- and post-instruments, the educational session itself was approximately 30 minutes of the overall 60 minutes.

In the qualitative arm of the research study, seven of the 56 nurses who participated in the education session, volunteered to participate in the individual audio-recorded interviews between three to four weeks following the education session. Approximately one week after an education session was conducted; participants who consented to involvement in instrument completion and the interview portion of the study were contacted by email to arrange for an individual interview to take place between three to four weeks after the educational session. This span of time was chosen to enable participants to have an opportunity to apply the new knowledge in practice.

A reminder email was sent to participants one week after the original email message. The interviews took place in a location and at a time preferable to the participant. Interview options include three different methods: three chose face-toface, three chose telephone, and one chose Skype contact. The interviews were conducted by the primary researcher using a semi-structured interview guide were digitally audiorecorded, and the information was then transcribed verbatim by a transcriptionist for purposes of qualitative analysis.

\subsection{Data analysis}

The SPSS Version 22 software $^{[40]}$ was used for statistical analysis of the quantitative data for this study. Demographic variables of gender, age, years worked as an RN, years worked on the unit and educational background were included in the analysis. Descriptive statistics are expressed as means, frequencies and percentages. Pre- and post-test comparisons were made using t-tests to determine if there was a statistical difference between the pre- and post-test results.

\section{RESULTS}

\subsection{Demographics}

A total of 56 participants, at two Southwestern Ontario acute care facilities were involved in the education session portion of the study. The sample included 47 females and 7 males; two participants did not provide an answer when filling out the gender related question on the demographic form.

The participants who attended the education session ranged in age from under 25 years of age to 56 years of age or older; twenty-three participants $(43 \%)$ reported to be within the range of 41 to 55 years of age. Eighteen (33\%) of the participants reported to have worked for 2 to 5 years as an $\mathrm{RN}$ and fourteen (26\%) reported to have worked for greater than 
25 years; fifteen (28\%) of the participants reported to have worked on their current unit for 2 to 5 years. Thirty-three (61\%) of the 56 participants reported having a Bachelor of Science in Nursing $(\mathrm{BScN})$ degree.

\subsection{Hypothesis one}

Results supported hypothesis one in that nurses had a higher level of knowledge about the care of delirious clients as it relates to the assessment, screening and management, after participating in the education session. Results of a paired t-test, using the pre- and post-educational session knowledge instrument data, indicated that the overall mean score for 56 participants on the post-test knowledge instrument $(\mathrm{M}=$ $6.95, \mathrm{SD}=1.56)$ was significantly greater $(p \leq .001)$ than the overall mean score of the pre-test knowledge instrument $(\mathrm{M}=3.29, \mathrm{SD}=1.52)$. These results indicate that a small, positive correlation exists between these two variables $(r=$ $.29, p \leq .028)$ suggesting that those participants who scored high on the pre-test instrument tended to score higher on the post-test instrument.

\subsection{Hypothesis two}

Hypothesis two was supported by the study results. Nurses had higher ratings of self-efficacy for assessment, screening and management of the clients at risk of developing delirium and for clients experiencing acute delirium after participating in the education session. The paired $t$-test indicated that for the 56 participants who completed the instruments, the overall mean score of the post-self-efficacy instrument $(\mathrm{M}=$ $7.73, \mathrm{SD}=.88)$ was significantly greater $(p \leq .001)$ than the overall mean pre-self-efficacy score $(\mathrm{M}=5.52, \mathrm{SD}=1.73)$. A moderate, positive correlation was found between pre- and post-test scores $(r=.33, p \leq .025)$, suggesting that participants that scored high on the pre-test instrument tended to score higher on the post-test instrument.

The pre and post-self-efficacy instruments, containing eight items each, were assessed for internal consistency with the participants' $(\mathrm{N}=56)$ data. Reliability coefficients range between 0.00 and $1.00,{ }^{[39]}$ therefore the higher the coefficient, the more dependable the measure of internal consistency. Polit and Beck ${ }^{[39]}$ suggest that alpha reliability coefficients greater than 0.8 are traditionally considered as a good reflection of internal consistency.

The pre-self-efficacy instrument, Cronbach alpha reliability coefficient was 0.94 , which indicates strong internal consistency among the pre-self-efficacy instrument items. The post-self-efficacy instrument, Cronbach alpha reliability coefficient resulted in an alpha of 0.90 , which can be reported as a strong internal consistency among the post-self-efficacy instrument items.

Published by Sciedu Press

\subsection{Research question}

The second arm of this study explored nurses' experiences of applying knowledge about caring for the client at risk for delirium and for the client experiencing acute delirium to practice, after participating in an education session. Interviews $(\mathrm{n}=7)$ were audio-recorded and then transcribed verbatim. The audio-recordings were first listened to while checking what was heard against the transcribed information to ensure consistency. Content analysis was conducted and initial categories were noted as empathy, knowledge acquisition, competence, leadership, and confidence. Themes were developed based on the categories, which served to highlight the essence of the participants' experience. Themes that emerged from analysis of the interview data were: enhancing emotional intelligence, strengthening clinical judgment to enhance quality of care, and increasing competency of family care.

\subsubsection{Enhancing emotional intelligence}

After involvement in the educational session, participants (nurses) became more consciously aware of and in control of themselves in practice. The nurses who participated in the education session were found to be engaging in selfmanagement behaviours, expressing their emotions and handling their relationships with clients empathetically, when working with clients at risk for or who were experiencing delirium.

The participants, in recognizing and being more aware of their own feelings and emotions as a result of the educational sessions, also expressed a sense of competence in caring for their clients: ... Well I am not as apprehensive, I guess, when I hear that it was kind of a sleepless night for them and, and they look a little bit suspicious around the room and, I used to be quite apprehensive approaching that patient when I hear in report about that's what they kind of look like in the morning and just to be calm about it and, I guess my calmness in, you know, that feeling goes to the patient as well so that they're a little bit more, I guess cooperative... (Participant 1)

After being involved in the education session, participants' shared that they were able to be more empathetic towards delirious clients. The participants discussed the ability to regulate emotions more effectively when providing care to those at risk of delirium. Enhanced emotional intelligence as a result of knowledge gained from the education session, emanates through the following participant's comments: ... It's easy to be more empathetic of them and reassuring to the families because I'm sure they have no idea what's going on and your approach is kind of gentle with them, you know, because, they're not thinking right, and not trying to, in any 
way, you know, escalate that behavior. (Participant 3)

Portraying a sense of awareness of the client's emotions, an aspect of emotional intelligence, resonated through the participants' interviews: ... It just made me think of the client more as a whole person keeping in mind the amount of sleep they've had or not had in the last couple of days. . anything like that in being out of their element just to keep all of those things in mind, and trying to ease them into, transition to like the hospital setting and who we are just to continue to reinforce where they are and that they'll be safe. (Participant 1)

In keeping with the theme of enhanced emotional intelligence, the concepts of being aware of another's feelings and empathy, continues to be evident throughout the participants' experiences: ... I was able to look at the whole picture of my client holistically and I was able to recognize in a timelier manner what was going on. (Participant 6) ... I am more aware of what the patient is going through, being more patient... I know what to expect and go from there... I guess, empathize with the patient more. Well it makes me more of a competent nurse, I think, more knowledgeable. (Participant 2)

The interviews provided insight into meaningful experiences of interactions with clients and their families, which suggested use of elements underpinning emotional intelligence in the care of the client at risk for delirium or for those experiencing acutely delirium.

\subsubsection{Strengthening clinical judgment to enhance quality of care}

Increasing clinical knowledge and applying that knowledge to practice enables nurses to provide quality care. Clinical judgement is the interpretation or inference of a clients health issues and the decision, on the part of the nurse, to take action or modify as appropriate dependent on the clients response. ${ }^{[45]}$ The educational session provided to those who participated in this study, is a step in the process of supporting nurses' abilities to translate knowledge into practice. In addition, the meaningful insights emanating from participants' interview data supports the notion that education sessions can positively influence nurses' clinical practice and contribute to their competency (knowledge) in caring for the client at risk for and those clients experiencing acute delirium in a hospital setting.

Participants' application of knowledge to practice, as a result of being involved in the education session was shared in the following ways by participants: ... So having those tools, knowing that they actually exist has definitely improved my way of assessing the patients... with regards to management, because as your presentation talked about there's the restless kind of delirium and then there's the somnolence, then I'm paying more attention on the, more somnolent ones because usually you think, we think, oh, it's just the narcotics or they're just really tired so then I'm trying to assess more of those patients to see if it, it could be delirium as well, whereas before I didn't really attribute the somnolence stage of delirium to be actually delirium. I treated it something else so now I'm looking for those in my practice right now... I've learned, and I, I'm trying to apply what I've learned... about delirium. (Participant 5)

An outcome of the knowledge applied from the education session was that nurses believed they could more readily recognize, diagnose, and provide treatment in a timelier manner: ... So what I would say is that I was not aware of the different analyzing tools that were present to me... I had not used them in my previous practice. And, they were very informative to me and my abilities to assess my patient in a different way when I would have them experience acute delirium, which happens often on our floor... I was able to recognize in a more timely manner what was going on and look at the, all my information and be able to diagnose my client quicker and get treatment faster and be able to help in the treatment plan. (Participant 6)

Further evidence that participating in clinical education contributes to nurses' competency (knowledge) and self-efficacy (confidence), resulting in positive influences in the nurses' clinical practice, is discussed during the interviews. The participants mention an ability to teach others with the knowledge and skills acquired from education session: ... Well for future, like, future scenarios I can now like teach other people, like students, I can tell them what to expect... What to look for... and what to do. (Participant 2)

\subsubsection{Increasing competency of family care}

Leadership is at the core of nursing. In an article pertaining to leadership and responsive care, McKenzie and Manley ${ }^{[46]}$ stated that nurses display leadership by being person-centred, through listening, interpreting and confirming understanding. Leadership also involves working with clients, colleagues, families and caregivers, along with evaluating and reflecting on the effectiveness of those interactions. ${ }^{[46]}$

Characteristics associated with leadership include: knowledge, judgement, emotional intelligence, independence, adaptability, self-confidence, social participation, and interpersonal skills. ${ }^{[47]}$ The acquisition of knowledge (competence) contributes to becoming a leader and enhancing an individual's self-efficacy (confidence), positively enhancing nursing performance. ${ }^{[48]}$ 
The experiences shared by the participants following the education session pertaining to the care of the client at risk for delirium and for those experiencing delirium in a hospital setting, resulted in participants' perceptions of an increase in leadership competency and positively influenced their role as nurses in clinical practice: ... it makes me a better teacher for sure, because we're always doing health teaching, so that's, I'm able to provide more information to the families and I just feel better, better able to deal with these situations when they come up. (Participant 4)

The meaningful involvement shared by participants attributes newly acquired knowledge from the education session to positively affecting the professional relationship with clients and families: ... I am able to make a more informed decision and also to provide explanation for the family and sound more knowledgeable, ... I was more knowledgeable in my explanation for the family so that they would feel better. (Participant 6)

\section{Discussion}

Both hypotheses were supported by the quantitative data. Overall, nurses gained knowledge in the recognition and management of delirium. Consistent with previous re$\operatorname{search}^{[8,18,49]}$ this study demonstrated that education had a positive influence on the knowledge of nurses with respect to the recognition and management of the delirious client population.

The significant change seen in the pre-test knowledge instrument scores $(\mathrm{M}=3.29, \mathrm{SD}=1.52)$ to the overall post-test mean score $(\mathrm{M}=6.95, \mathrm{SD}=1.56)$ in the current study is comparable to the increase in the average score found by McCrow and colleagues, ${ }^{[8]}$ who examined delirium knowledge following participation in a web-based delirium education intervention. This finding provides support that education can increase nurses' knowledge, and is important to continue throughout pre-graduate education and post-graduate practice.

Tabet and colleagues ${ }^{[18]}$ and Wand and colleagues ${ }^{[49]}$ studied the effects of education on the incidence of delirium. Findings from these studies provided support that education provided to nurses about the recognition of delirium influences incidence of delirium. Results from these studies differ from the current study, in that, incidences of delirium were also analyzed using data collected from client populations. Both Tabet and colleagues ${ }^{[18]}$ and Wand and colleagues ${ }^{[49]}$ compared data collected that measured nurses' perception of delirium in client's pre- and post-intervention. Results showed a decrease in perceived incidences of delirium following the nurses receiving education pertaining to delirium

Published by Sciedu Press recognition and management. These findings suggest that by providing education to nurses it is believed recognition and care of the delirious clients by nurses will be positively influenced as a result of the education.

Second, as a result of participating in the clinical education session, nurses had higher ratings of self-efficacy for assessment, screening and management of the clients at risk of developing delirium and for clients experiencing acute delirium after participating in the education session. This study result suggests that nurses who think they can assess for and manage delirious clients, are more likely to engage in future behaviours that could decrease exacerbations or incidences of delirium.

Feelings of increased self-efficacy of caring for the client with or at risk of experiencing delirium were made evident through the shared experiences of the participants in the interviews. Similarly, findings from a study by Babenko-Mould and colleagues ${ }^{[50]}$ reported increased levels of self-efficacy for professional practice competencies as a result of the influence of computer conferencing support and peer connectivity.

The qualitative findings highlighted participants' meaningful insights themes of enhancing emotional intelligence, strengthening clinical judgment to enhance quality of care, and increasing competency of family care to be identified. These themes served to capture the essence of participants' participation. Application of knowledge acquired from the education session material to practice enabled nurses to experience firsthand the effects of the translation of knowledge on ones' emotional intelligence. Participants reported an increased awareness of their own feelings and emotions as a result of the education sessions. The concept of increased awareness of one's own beliefs was evident in the qualitative data provided in the study Pike and O'Donnell. ${ }^{[51]}$ A participant shared experiences of high levels of self-efficacy in relation to dealing with a cardiac arrest following a clinical simulation session. The participant then described being aware of a change in efficacy that she could perform once presented with the real-life situation.

Nurses reported having the ability to have a keener sense of awareness of the clients' emotions. Experience shared by one participant, provided evidence that as a result of being involved in the education session provided knowledge that enabled the nurse to perceive herself as being more competent in the area of delirium client care practices. The participant stated that, knowing there are tools to use to assess clients and understanding how to use them "has definitely improved my way of assessing patients". (Participant 5)

Previous studies examining delirium education for nurses, 
such as a quality improvement project by Solberg, Plummer, May, and Mion, ${ }^{[52]}$ presented similar results as those found in this study. Solberg and colleagues ${ }^{[52]}$ evaluated a quality improvement program where nurses were educated to use a structured bedside assessment tool for delirium in practice. The authors found that the quality improvement program resulted in nurses' implementation and adoption of a bedside delirium tool, ${ }^{[52]}$ which assisted them with early recognition and treatment.

Finally, participants attributed the newly acquired knowledge received from participating in the education session as positively affecting relationships with clients and their families. The current study shared participants' experiences of strengthened empathy, which allowed participants to provide reassurance to clients and families. As a result of the knowledge translated through the education session, feelings of increased empathy toward the client and the family allowed participants the ability to provide quality care. Participants described feelings of empathy towards the client as a result of the knowledge provided in the education session. The distress that families live through during an elderly hospitalized client's delirious episode requires supportive information to assist in the understanding of delirium, the care and support needs. ${ }^{[53]}$

\subsection{Recommendations}

Delirium education is recommended to strengthen nurses' knowledge and self-efficacy of caring for clients with delirium. Education programs should be provided by organizations as a form of continuous professional development for nurses and should be aligned with evidenced-informed practices. In this way, education being delivered can be consistent, and effective management of these clients will become a standard practice of care. A recommendation to increase awareness of delirium would involve collaboration between nursing academic and acute care settings. Students and nurses already working with clients in hospitals could be educated as to how to screen for delirium using a standardized screening tool. Implementation of facility-wide mandatory screening may decrease the negative consequences associated with delirium. A potential increase in recognition prior to exacerbation can provide the client, family, nurse, and other interdisciplinary team members with potentially less negative outcomes.

\subsection{Limitations}

The results of the study are limited to the specific context of the two facilities involved. The size of the sample was smaller than anticipated, possibly due to the timing of education sessions coinciding with implementation of corporate change to order entry and computer system upgrades. Replication of this study would strengthen standardization of the researcher-designed instruments.

\section{Conclusion}

Following the education session concerning the recognition and management of delirious hospitalized clients, nurses' knowledge, and self-efficacy for the care of those clients with or at risk of delirium was found to have increased. The translation of knowledge obtained through the education session allowed nurses to experience beliefs of increased self-efficacy for the care of delirious clients.

Delirium is one of the most common conditions found in the acute clinical setting, yet it remains one of the least recognized and understood conditions. Studies, such as this, demonstrate the influence CPD programs in nursing have on client health care outcomes. Assessing nurses' knowledge and self-efficacy of caring for clients experiencing delirium and those at risk of developing delirium in a hospital setting prior to and immediately after taking part in a clinical education session provided findings that support a need for ongoing nursing education. Exploring nurses' experiences of applying knowledge from the education session to the practice setting allowed the researcher to understand the influence education has on nurses' beliefs of self-efficacy. Therefore, there is value in delivering CPD programs to nurses to increase their knowledge and self-efficacy for caring for delirious clients, translating to positive outcomes for clients and their families.

\section{ACKNOWLEDGEMENTS}

The authors acknowledge study funding support through a chapter of Sigma Theta Tau International Honor Society of Nursing.

\section{Conflicts of InTEREST Disclosure}

The authors declare that there is no conflict of interest.

\section{REFERENCES}

[1] Aslan M, Koroglu A, Celik FH, et al. An evaluation of cases with delirium in a training hospital. The Journal of Psychiatry and Neurological Sciences. 2011; 24(2): 121-127.

[2] Burns A, Gallagley A, Byrne J. Delirium. Journal of Neurology, Neu- rosurgery and Psychiatry. 2004; 75(3): 362-367. http://dx.doi.o rg/10.1136/jnnp. 2003.023366

[3] Kaplan NM, Palmer BF. Etiology and Management of Delirium. [Southwestern Internal Medical Conference]. The American Journal of Medical Sciences. 2003; 325(1): 20-30. http://dx.doi .org/1 
$0.1097 / 00000441-200301000-00005$

[4] Fong TG, Tulebaev SR, Inouye SK. Delirium in elderly adults: Diagnosis, prevention and treatment. Nature reviews. Neurology. 2009; 5(4): 210-220. PMid:19347026 http://dx.doi.org/10.1038/n rneurol.2009.24

[5] Rice K, Bennett M, Gomez M, et al. Nurses' recognition of delirium in the hospitalized older adult. Clinical Nurse Specialist. 2011; 25(6): 229-311. PMid:22016018 http://dx.doi.org/10.1097/NUR. 0 b013e318234897b

[6] Balasundaram B, Holmes J. Delirium in vascular surgery. European Journal of Vascular and Endovascular Surgery: The Official Journal of the European Society for Vascular Surgery. 2007; 34(2): 131134. PMid:17498980 http://dx.doi.org/10.1016/j.ejvs. 20 07.02 .016

[7] Flinn DR, Diehl KM, Seyfried LS, et al. Prevention, diagnosis, and management of postoperative delirium in older adults. Journal of the American College of Surgeons. 2009; 209(2): 261268. PMid:19632604 http://dx.doi.org/10.1016/j. jamcoll surg. 2009.03.008

[8] McCrow J, Sullivan K, Beattie ER. Delirium knowledge and recognition: A randomized controlled trial of a web-based educational intervention for acute care nurses. Nurse Education Today. 2014; 34(6): 912-917. PMid:24393287 http://dx.doi.org/10.1016 /j.nedt.2013.12.006

[9] Rudolph JL, Schreiber K, Harrington MB. Postoperative delirium: Overview and Opportunities to Optimize Outcomes. Journal of Clinical Outcomes Management. 2008; 15(10): 502-517.

[10] Meagher D, Leonard M. The active management of delirium: Improving detection and treatment. Advances in Psychiatric Treatment. 2008; 14(4): 292-301. http://dx.doi.org/10.1192/apt.bp. 107.003723

[11] Weber JB, Coverdale JH, Kunik ME. Delirium: Current trends in prevention and treatment. Internal medicine journal. 2004; 34(3): 115-121. PMid:15030459 http://dx.doi.org/10.1111/j.144 4-0903.2004.00549.x

[12] Chaput AJ, Bryson GL. Postoperative delirium: Risk factors and management: Continuing professional development. Canadian Journal of Anaesthesia. 2012; 59(3): 304-320. PMid:22311257 http: //dx.doi.org/10.1007/s12630-011-9658-4

[13] Schofield I, Dewing J. The care of older people with a delirium in acute care settings. Nursing Older People. 2001; 13(1): 215. PMid:12008405 http://dx.doi.org/10.7748/nop2001.03. 13.1.21.c2167

[14] Attard A, Ranjith G, Taylor D. Delirium and its treatment. CNS Drugs. 2008; 22(8): 631-644. http://dx.doi.org/10.2165/0 0023210-200822080-00002

[15] Mistarz R, Eliott S, Whitfield A, et al. Bedside nurse-patient interactions do not reliably detect delirium: An observational study. Australian Critical Care: Official Journal of the Confederation of Australian Critical Care Nurses. 2011; 24(2): 126-132. PMid:21514176 http://dx.doi.org/10.1016/j.aucc. 2011.01.002

[16] Tabet N, Howard R. Prevention, diagnosis and treatment of delirium: Staff educational approaches. Expert Review of Neurotherapeutics. 2006; 6(5): 741-751. PMid:16734522 http://dx.doi.org/10. 1586/14737175.6.5.741

[17] Evans LK. Complex care needs in older adults with common cognitive disorders. Section B: Assessment in management of delirium (Acute confusion States). 2007. Available from: http://hartfordign.org/uploads/File/gnec_stat e_of_science_papers/gnec_delirium.pdf

[18] Tabet N, Hudson S, Sweeney V, et al. An educational intervention can prevent delirium on acute medical wards. Age and Ageing. 2005;
34(2): 152-156. PMid:15713859 http://dx.doi.org/10.1093 /ageing/afi031

[19] Bandura A. Self-efficacy: Toward a unifying theory of behavioral change. Psychological Review. 1977; 84: 191-215. http: //dx.doi.org/10.1037/0033-295X.84.2.191

[20] Bandura A. Social foundations of thought and action. Englewood Cliffs, NJ: Prentice-Hall, 1986.

[21] Zulkosky K. Self-efficacy: A concept analysis. Nursing Forum. 2009; 44(2): 93-102. http://dx.doi.org/10.1111/j.1744-6 198.2009.00132.x

[22] Robb M. Self-efficacy with application to nursing education: A concept analysis. Nursing Forum. 2012; 47(3): 166-172. PMid:22861653 http://dx.doi.org/10.1111/j.1744-6198.2012.00267.x

[23] Jordan K, Church T. A clinical learning experience: Enhancing baccalaureate nursing students' self-efficacy in meeting the psychosocial needs of clients with dementia. Journal of Nursing Education. 2013; 52(3); 171-174. PMid:23410253 http://dx.doi.org/10.3928 101484834-20130218-03

[24] Roh Y, Lee W, Chung H, et al. The effects of simulation-based resuscitation training on nurses' self-efficacy and satisfaction. Nurse Education Today. 2013; 33(2): 123-128. PMid:22153054 http: //dx.doi.org/10.1016/j.nedt.2011.11.008

[25] Stanley M, Pollard D. Relationship between knowledge, attitudes, and self-efficacy of nurses in the management of pediatric pain. Continuing Nursing Education. 2013; 39(4): 165-171.

[26] Akechi T, Ishiguro C, Okuyama $\mathrm{T}$, et al. Delirium training program for nurses. Psychosomatics. 2010; 51(2): 106-111. http: //dx.doi.org/10.1016/S0033-3182(10)70670-8

[27] Meako ME, Thompson HJ, Cochrane BB. Orthopaedic nurses' knowledge of delirium in older hospitalized patients. Orthopaedic nursing/National Association of Orthopaedic Nurses. 2011; 30(4): 241248. PMid:21799379 http://dx.doi .org/10.1097/NOR. 0b013 e3182247c2b

[28] Straus SE, Tetroe J, Graham I. Defining knowledge translation. Canadian Medical Association Journal. 2009; 181(3-4): 165-168. PMid:19620273 http://dx.doi.org/10.1503/cmaj.081229

[29] Bjørk IT, Lomborg K, Nielsen CM, et al. From theoretical model to practical use: An example of knowledge translation. Journal of Advanced Nursing. 2013; 69(10): 2336-2347. PMid:23387968 http://dx.doi.org/10.1111/jan.12091

[30] Graham ID, Logan J, Harrison MB, et al. Lost in knowledge translation: Time for a map? The Journal of Continuing Education in the Health Professions. 2006; 26(1): 13-24. PMid:16557505 http://dx.doi.org/10.1002/chp. 47

[31] Johnson K, Brown P, Harniss M, et al. Knowledge Translation in Rehabilitation Counseling. Rehabilitation Education. 2010; 24: 239-248. http://dx.doi.org/10.1891/088970110805029714

[32] Doran D, Sidani S. Outcomes-focused knowledge translation: A framework for knowledge translation and patient outcomes improvement. Worldviews on Evidence-Based Nursing. 2007; 4(1): 3-13. PMid:17355405 http://dx.doi.org/10.1111/j.1741-6 $787.2007 .00073 . \mathrm{x}$

[33] Heyland DK, Cahill NE, Dhaliwal R. Lost in (knowledge) translation. Journal of Parenteral and Enteral Nutrition. 2010; 34(6): 61015. PMid:21097761 http://dx.doi.org/10.1177/014860711 0361909

[34] Wallin L. Knowledge translation and implementation research in nursing. International Journal of Nursing Studies. 2009; 46: 576587. PMid:18674761 http://dx.doi.org/10.1016/j.ijnurst u. 2008.05 .006

[35] Cummings GG, Olivo SA, Biondo PD, et al. Effectiveness of knowledge translation interventions to improve cancer pain management 
Journal of Pain and Symptom Management. 2011; 41(5): 915 939. PMid:21398088 http://dx.doi.org/10.1016/j.jpainsy mman.2010.07.017

[36] Horeczko T, Enriquez B, McGrath N, et al. The pediatric assessment triangle: Accuracy of its application by nurses in the triage of children. Journal of Emergency Nursing. 2013; 39(2): 182189. PMid:22831826 http://dx.doi.org/10.1016/j.jen. 201 1.12 .020

[37] Christensen M. Patient group directions: The application and integration of knowledge in advancing nursing practice. Journal of Nursing Education and Practice. 2015; 5(2): 103-110. http://dx.doi.org /10.5430/jnep.v5n2p103

[38] Creswell JW. Research design: Qualitative, quantitative, and mixed methods approaches. Thousand Oaks, CA: Sage; 2009.

[39] Polit DF, Beck CT. Nursing research: Generating and assessing evidence for nursing practice (9th ed.). Philadelphia: Lippincott. 2012.

[40] IBM Corp. IBM Statistical Package for Social Sciences (SPSS) Statistics for Windows, Version 22.0. Armonk, NY: IBM Corp., 2013.

[41] Sandelowski M. Whatever happened to qualitative description? Research in Nursing and Health. 2000; 23: 334-340. http://dx.doi.org/10.1002/1098-240X (200008) 23: 4<334: : AID-NUR9>3.0.CO;2-G

[42] Sandelowski M. What's in a Name? Qualitative Description Revisited. Research in Nursing and Health. 2010; 33: 77-84. PMid:20014004

[43] Cohen J. Statistical power analysis for the behavioral sciences (2nd edition). Hillsdale, NJ: Lawrence Erlbaum. 1988.

[44] Registered Nurses Association of Ontario [RNAO]. Best Practice Guidelines (BPG). Recognizing Delirium, Dementia and Depression. 2015.

[45] Tanner C. Thinking like a nurse: A research-based model of clinical judgement in nursing. The Journal of Nursing Education. 2006; 45(6): 204-211.
[46] McKenzie C, Manley K. Leadership and responsive care: Principle of nursing practice. Nursing Standard. 2011; 25(35): 35-37. PMid:21667854 http://dx.doi .org/10.7748/ns2011.05.25. 35.35. c8496

[47] Marquis BL, Huston CJ. Leadership Roles and Management Functions in Nursing: Theory and Application (6th edition). Philadelphia, PA: Wolters Kluwer/Lippincott Williams and Wilkins; 2009.

[48] Lee TW, Ko YK. Effects of self-efficacy, affectivity and collective efficacy on nursing performance of hospital nurses. Journal of Advanced Nursing. 2010; 66(4): 839-848. PMid:20423371 http: //dx.doi.org/10.1111/j.1365-2648.2009.05244.x

[49] Wand APF, Thoo W, Sciuriaga H, et al. A multifaceted educational intervention to prevent delirium in older inpatients: A before and after study. International Journal of Nursing Studies. 2014; 51(7): 974-982. PMid:24332570 http://dx.doi.org/10.1016/j.ijn urstu. 2013.11.005

[50] Babenko-Mould Y, Andrususzyn M, Goldenburg D. Effects of computer-based clinical conferencing on nursing students' selfefficacy. Journal of Nursing Education. 2004; 43(4): 149-156.

[51] Pike T, O'Donnell V. The impact of clinical simulation on learner self-efficacy in pre-registration nursing education. Nurse Education Today. 2010; 30(5): 405-410. PMid:19883960 http://dx.doi .o $\mathrm{rg} / 10.1016 / \mathrm{j} \cdot \mathrm{nedt} .2009 .09 .013$

[52] Solberg LM, Plummer CE, May KN, et al. A quality improvement program to increase nurses' detection of delirium on an acute medical unit. Geriatric Nursing. 2013; 34(1): 75-79. http://dx.doi.org /10.1016/j.gerinurse.2012.12.009

[53] Toye C, Matthews A, Hill A, et al. Experiences, understandings and support needs of family carers of older patients with delirium: A descriptive mixed methods study in a hospital delirium unit. International Journal of Older People Nursing. 2014; 9: 200-208. PMid:23383980 http://dx.doi.org/10.1111/opn.12019 